in hospital study, whereas in our study snoring was subjectively assessed and perhaps better represents the usual situation at home. Furthermore, the femoral artery may not be an appropriate 'control' artery with which to compare the carotid for atheroma.

Abstract P200 Table 1 Degree of carotid artery stenosis in 'frequent' and 'non-frequent' snorers

\begin{tabular}{llll}
\hline & 'Frequent snorers' & 'Non-frequent' snorers & p-Value \\
\hline Carotid stenosis $\geq 30 \%$ & $43 \%$ & $48 \%$ & 0.44 \\
Carotid stenosis $\geq 50 \%$ & $16 \%$ & $21 \%$ & 0.42 \\
\hline
\end{tabular}

'Frequent snoring' $=$ snoring stated as $\geq 1-2 /$ times per week.

p-Values all determined by Fisher's Exact test.

REFERENCES

1. Lee SA, et al. Heavy snoring as a cause of carotid atherosclerosis. Sleep 2008;31:1207-13.

2. Gun Cho Jin, et al. Impaired endothelial-dependent vasodilatation in carotid arteries exposed to snoring-like vibrations. Am J Respir Crit Care Med 2010;181:A2466.

\section{P201 HEALTH LITERACY AND SLEEP APNOEA}

doi:10.1136/thx.2010.151068.2

R Ghiassi, M R Partridge. Imperial College, London, UK

Introduction We have previously demonstrated that $33 \%$ of new patients and $16 \%$ of serial users have difficulty completing the Epworth Sleepiness Scale (ESS). To explore reasons for this we assessed literacy in a further group of patients.

Methods 122 Sleep Centre and Lung Function laboratory patients were approached and assessed for level of functional literacy in medicine using the REALM questionnaire. A score $\leq 60$ suggests a literacy level that would struggle with patient education materials and prescription labels. Education and English language data were collected.

Results 86/92 (93.3\%) Sleep and 30/30 (100\%) Lung function (LF) patients completed REALM. $5(5.6 \%)$ in the Sleep group declined when shown the test. One did not complete due to time restrictions. Mean age was $51.2 \pm 11.8$ years Sleep and $56.1 \pm 17$ years LF. Mean age leaving formal education was $18.7 \pm 2.9$ years Sleep and $17.7 \pm 2.9$ years LF. In the Sleep cohort $24 \%(21 / 86)$ had a graduate and $15 \%(13 / 86)$ postgraduate education vs. LF $27 \%(8 / 30)$ graduate and $3 \%(1 / 30)$ postgraduate education. REALM scores are shown in Abstract P201 Table 1 grouped into the standard four ranges. 78\% (Sleep) and 83\% (LF) spoke English as their mother tongue; all patients used English as their everyday spoken language.

\section{Abstract P201 table 1}

\begin{tabular}{lllll}
\hline $\begin{array}{l}\text { REALM score } \\
\text { ranges }\end{array}$ & $\begin{array}{l}\text { Equivalent reading } \\
\text { age US school grade }\end{array}$ & UK age equivalent & $\begin{array}{l}\text { \% Sleep } \\
(\mathbf{n}=\mathbf{8 6})\end{array}$ & $\begin{array}{l}\text { \% Lung function } \\
(\mathbf{n}=\mathbf{3 0})\end{array}$ \\
\hline $0-18$ & 3rd grade or below & 8 years or less & 0 & 0.0 \\
$19-44^{*}$ & 4th/6th grade & 9-12 years & 1.2 & 3.3 \\
$45-60^{*}$ & 7th/8th grade & 12-14 years & 15.1 & 6.7 \\
$61-66$ & High School & $14-15$ years + & 83.7 & 90.0 \\
\hline
\end{tabular}

${ }^{*} \mathrm{~A}$ score $\leq 60$ suggests a literacy level that would struggle to cope with patient education materials and prescription labels.

Conclusions Assessing literacy in patients is not easy. We have previously shown how patients struggle to complete the ESS. Problems completing forms occur for many reasons and evidence suggests that clinicians overestimate patient literacy. We found evidence of impaired health literacy in $16.3 \%$ of Sleep and $10 \%$ of Lung function patients. That some Sleep patients declined to be tested once shown the questionnaire might suggest the $16.3 \%$ score is underestimated. Why Sleep patients should fare worse than LF patients is unclear especially when university and age leaving education were higher in the sleep cohort. All used English as their everyday language however fewer Sleep patients had English as their mother tongue. Cognitive deficits associated with undiagnosed obstructive sleep apnoea syndrome and increased sleepiness could conceivably be a contributory factor. This study suggests clinicians need to provide clinical material and information in a format that is comprehensible to a wide range of patients (such as pictorial format) and that Sleep patients may have special needs.

\section{P202 CLINICS FOR OBSTRUCTIVE SLEEP APNOEA HYPOPNOEA (OSAH)-TIME FOR A CHANGE?}

doi:10.1136/thx.2010.151068.3

T S Jordan, E Idris, R Haqqee, M Allen. University Hospital of North Staffordshire NHS Trust, Stoke-on Trent, UK

Introduction OSAH is a significant public health problem. Growing awareness and rising prevalence is increasing demand for sleep services. Many Trusts are unable to expand existing clinic space to meet this demand. In its recent White Paper ${ }^{1}$, the Government laid out its vision of a patient-centred NHS, pledging patients more choice and control over decision making about their care. However, a sizeable proportion of patients with suspected OSAH are from the working population, yet the NHS does not routinely provide clinics outside normal working hours.

Method Patients referred for suspected OSAH were randomly appointed to either daytime or evening clinics. Over a 3-month period, opinions of this out-of-hours service and problems encountered on attending the clinics were surveyed by questionnaire completed by patients in the waiting room.

Results Of 165 patients appointed, 156 attended and 136 (87\%) completed questionnaires (mean age 50.4 years (range 18-75), 74\% male). Over half (57\% [77/136]) were in employment of which $21 \%$ $(16 / 77)$ worked shifts and $79 \%$ (61/77) days. The rest (59/136 $(43 \%))$ were non-working due to disability $(42 \%(24 / 59))$, retirement (39\% [23/59]), were full-time carers $(10 \%$ [6/59]) or were unemployed (8\% [5/59]). Patient responses are detailed in Abstract P202 Table 1. In addition, 41\% (13/32) of workers seen in evening clinics felt that work would have been a problem if attending in the day. DNA rates were higher for daytime clinics $(7 \%)$ than evenings $(3 \%)$. The proportion of workers in the DNAs was unknown.

\section{Abstract P202 Table 1 Patient responses}

\begin{tabular}{lll}
\hline & Working patients & Non-working patients \\
\hline $\begin{array}{l}\text { Actual attendance } \\
\text { Daytime clinics }\end{array}$ & $58 \%(45 / 77)$ & $66 \%(39 / 59)$ \\
Evening clinics & $42 \%(32 / 77)$ & $34 \%(20 / 59)$ \\
Preference & & \\
Daytime clinics & $23 \%(18 / 77)^{*}$ & $53 \%(31 / 59)$ \\
Evening clinics & $55 \%(42 / 77)$ & $12 \%(7 / 59)$ \\
No preference & $22 \%(17 / 77)$ & $36 \%(21 / 59)$ \\
Problems encountered-daytime clinics & \\
Work & $62 \%(28 / 45)$ & - \\
Transport & $9 \%(4 / 45)$ & $13 \%(5 / 39)$ \\
Car parking & $9 \%(4 / 45)$ & $46 \%(18 / 39)$ \\
Partner availability & $4 \%(2 / 45)$ & $13 \%(5 / 39)$ \\
Problems encountered-evening clinics & \\
Work & $3 \%(1 / 32)$ & - \\
Transport & $0 \%(0 / 32)$ & $15 \%(3 / 20)$ \\
Car parking & $22 \%(7 / 32)$ & $30 \%(6 / 20)$ \\
Partner availability & $3 \%(1 / 32)$ & $0 \%(0 / 20)$ \\
\hline
\end{tabular}

*Included 33\% working shifts. 
Conclusions There is a considerable demand for out-of-hours sleep clinics. This is predominantly from those in employment. Making up a large proportion of patients referred for suspected OSAH, over half of these patients preferred evening clinics. Provision of this clearly demanded service requires a change in current working practice. Not only would out-of-hours clinics be a move towards delivering the patient-centred NHS pledged in the recent Government White Paper ${ }^{1}$, but would deliver the increased clinic capacity required to meet rising demand.

${ }^{1}$ Equity and Excellence: Liberating the NHS. DoH. July 2010.

\section{P203 MANAGEMENT OF OBESITY IN RESPIRATORY CLINICS-ARE WE DOING ENOUGH?}

doi:10.1136/thx.2010.151068.4

S Mandal, D J Powrie. Southend University Hospital, Southend, UK

Introduction and Objectives Obesity is a growing problem and as Respiratory Physicians we are encountering more patients in clinics with co-morbidities associated with obesity. We wished to determine what services were available to patients with respiratory disease and obesity.

Methods We carried out a postal survey of respiratory departments in the UK.

Results 211 surveys were sent out and 100 were returned. 57 hospitals ran specialist sleep clinics, of those that did not have specialist clinics 41 saw obese patients in their general respiratory clinics. We asked about baseline measurements taken in clinic (BMI, waist circumference and collar size); 1 unit took no measurements; 23 took 1 measurement (most commonly BMI) and 60 took 2 measurements and 16 took all 3 measurements. 95 respondents gave their patients advice regarding the management of obesity. 1 hospital had a dietician available in clinic, 89 referred to a dietician; however, 10 had no access to a dietician at all. Physicians were asked about screening for co-morbidities. 81 units screened for hypertension, of these 47 (58\%) referred back to the GP for management, $12(15 \%)$ treated the hypertension themselves and 3 referred to specialists. 43 screened for diabetes, of these 18 (42\%) referred to the GP for management, 2 treated the diabetes themselves and 10 (23\%) referred to specialists. 16 screened for hypercholesterolaemia, 8 referred to the GP for management and $3(19 \%)$ treated the hypercholesterolaemia themselves. Physicians were asked what other forms of advice/services were available in clinic, Abstract P203 Table 1. Clinicians were asked to rate on a scale of $1-10$ about how happy they were with their current service, the average score was 4.55 . We then asked how they felt their service could be improved, most commonly clinicians felt a dietician should be present in clinic $(\mathrm{n}=22)$ and that the service/clinic should be in a multidisciplinary format $(n=16)$. Despite obesity and its co-morbidities being common, management in clinics is variable, as is access to services. An integrated pathway for the management of obesity may improve outcomes.

Abstract P203 Table 1 Modes of advice available in clinic

\begin{tabular}{lc}
\hline Advice given & Number \\
\hline Diet sheet & 24 \\
Refer to dietician & 80 \\
Exercise & 17 \\
Refer to obesity clinic & 29 \\
Refer to surgeons & 25 \\
No advice & 5 \\
\hline
\end{tabular}

\section{P204 TRAVEL WITH CPAP MACHINES: HOW FREQUENT AND WHAT ARE THE PROBLEMS?}

doi:10.1136/thx.2010.151068.5

S Faruqi, P Carveth-Johnson, A O C Johnson. Pontefract General Infirmary, Pontefract, UK

Introduction and Objectives Obstructive sleep apnoea (OSA) is common and most patients are relatively young. CPAP is the standard treatment. This questionnaire survey aimed to improve the understanding of the problems which patients on CPAP face during travel and while away from home.

Methods 150 patients on CPAP were randomly selected from our patient database and sent a postal questionnaire. They were asked the number of times they had travelled in the last 2 years and specific questions about the last three trips. These included mode of travel, duration of trip, change in CPAP use, problems with transport and use of CPAP. Patients were asked to specifically document whether they used CPAP during travel. All patients are offered a letter regarding their CPAP therapy to facilitate travel.

Results 101 questionnaires were returned (men=69, mean age $=60.5$ years). 58 ( $\mathrm{men}=50$, mean age 59.4 years) had travelled in the last 2 years on 211 occasions. Data were collected for 139 trips. In 13 trips the CPAP machine was not taken. Reasons included weight, space and check in concerns. 84 trips were within Europe and 7 to North America. 93 trips were by air. On 22 trips, respondents reported the "CPAP letter" was needed for check in. In 7 of the 93 trips by air, problems with checking in the CPAP machine were encountered. In all but 4 trips the CPAP machine was carried as hand luggage. In 33 trips problems with use of CPAP due to the short power cord was reported. CPAP was used less often abroad. CPAP was rarely used during travel. Individual statements highlighted problems with security and check-in.

Conclusions Patients with OSA travel abroad frequently and usually take their CPAP machine with them. In a significant number there are problems with check-in of the CPAP machine and we strongly recommend patients are provided with a "CPAP letter". Improved dissemination of information is needed to patients and airport staff regarding OSA and CPAP. We recommend patients carry extension cords and power adaptors. The reason for less use of CPAP abroad is not clear and needs further explanation.

\section{P205 OBSTRUCTIVE SLEEP APNOEA SCREENING-COST AND CLINICALLY EFFECTIVE IN A TIA CLINIC?}

doi:10.1136/thx.2010.151068.6

M Waller, A Hussey, A Morris, D Hargroves, B Prathibha. William Harvey Hospital, Ashford, UK

Several large epidemiological studies have shown a strong association between OSA and the development of cerebrovascular disease and there is growing evidence to support this finding. These include Transient Ischaemic attacks and stroke. There is increased morbidity and mortality rates in these patients. Conversely patients with Strokes are at increased risk of developing obstructive and central sleep apnoea. Early recognition and treatment of Obstructive sleep apnoea has been shown to prevent cerebrovascular events.

Aim To assess the prevalence of cerebrovascular events in a cohort of patients diagnosed with obstructive sleep apnoea in Ashford.

Methods 100 patients with a confirmed diagnosis of OSA were randomly selected to enter the study. Detailed data, about their demographics, co morbidities as well as sleep, were collected. 